Marcello Amoruso, Mari D’Agostino

\title{
Teenage and adult migrants with low to very low education levels: learner profiles and proficiency assessment tools
}

Abstract: This article presents data and student experiences acquired within the
frame of the inclusion project of the Italian Language School for Foreigners at
the University of Palermo. The programme, established five years ago, has cre-
ated and provided educational courses for adults and unaccompanied minors
of low to very low schooling level, most of them between 16 and 18 years old.

Résumé : Le rapport présente les profils d'étudiants et les expériences acquises dans le cadre du " Projet d'inclusion dans l'Ecole de langue pour l'italien Langue étrangère “ de l'université de Palerme. Le programme, créé il y a cinq ans, dispense des cours à des adultes et à des mineurs non accompagnés ayant un niveau d'instruction faible à très faible, la majorité ayant entre 16 et 18 ans.

\section{New arrivals and old faces welcomed}

Our project began in early July 2012 in Palermo, a multilingual city (D’Agostino 2012, 2015b, 2015c). While schools and youth centres close for the yearly summer break, the ex Convento di Sant'Antonino, home of the University of Palermo's Italian Language School for Foreigners, buzzes with life. For many years now, young people from all over the world have been attending intensive summer courses at the school, where they study Italian language and culture, but also learn about different lifestyles, fall in love and make lifelong friendships. As well as lots of students from international communities, an increasing number of adult migrants (often refugees or asylum seekers) have been attending the courses, most of them highly educated people who need to learn their host country's language as soon as possible.

During summer 2012, the school began to receive more and more requests for incoming students. At our office door, for the first time ever there were also young people looking lost and bewildered, accompanied by their child care in-

Marcello Amoruso, University of Palermo, Italy, E-mail: marcello.amoruso@gmail.com

Mari D’Agostino (corresponding author), University of Palermo, Italy,

E-mail: mari.dagostino@unipa.it

DOI 10.1515/9783110477498-047, (cc)BY-NC-ND (c) 2017 Marcello Amoruso, Mari D’Agostino, published by De Gruyter.

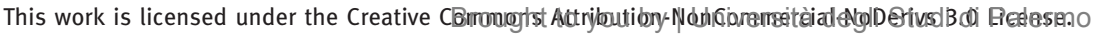


stitution tutor. The official name for these new students is "unaccompanied foreign minors". From the start of the project until now almost 1000 minors have taken part in our courses. Many of them come from Bangladesh, though the vast majority come from Western African countries such as Gambia, Senegal, Mali, Ghana, Nigeria, Ivory Coast, Guinea, Guinea-Bissou and Sierra Leone. Many are of Arab origin, coming from North Africa, mainly from Egypt and Tunisia. In terms of their level of education, only a few students have had more than five years of schooling, very few of them have had eight, and $30-40 \%$ are completely illiterate (Amoruso et al. 2015; D’Agostino 2015a; Amoruso and D'Agostino 2016a, 2016b). We did not know how challenging this was going to be as we knew very little about the learner profile of an unaccompanied foreign minor. We also did not know how much the presence of these new students would change the normal teaching structure and layout of our school. For these "boat kids", what would be appropriate teaching material? What outdoor activity might be of interest to them? And above all, how would we integrate new and old students? After a couple of weeks we knew that adding one more chair in the classroom wasn't sufficient, we needed to make bigger changes.

\section{The language course: a meeting place}

From the beginning we realized that in our classrooms there was an unusual mix of people from very different backgrounds. But they were sharing time and space, exercise sheets, scissors, and songs just like in any other class at the start of any Italian language course in any part of the world. Where and how could we imagine such different worlds - in terms of experience, everyday life and future expectations - would meet? The setting of this unlikely meeting was the University of Palermo.

It was there that young people met educated people, and their worlds suddenly became full of books and hopes for the future, along with the desire to go and see the world. These young people were often without parents, fleeing from tragic events involving their families or countries, living in a state of uncertainty, often in hostile environments over which they had little control. Nonetheless, they were full of hope for the future, having had to adapt to such horrible circumstances. Teaching and educational changes were more important than our own failures and frustrations. In the class, the minors could integrate with different cultures and different ways of living and behaving, something very different from what they were used to. The mixed nature of the group also allowed the other students to get to know cultures and lifestyles that they had only ever seen on TV. They also learnt to give faces and names to the empty labels that 
the media regularly shows us. They learnt to see the human behind the label, their history, their love for their family, friends, homeland, from whom they were so far that their only connection was through the screen of their mobile phone. All students also took part, without even realizing it, in an integration project which belongs to Palermo and all of Italy. After all, are integration policies not an important part of culture? The meeting of the two groups of students was enriching for both parties: between the walls of a language classroom the minors discovered new opportunities that were previously unheard of and the others opened their eyes to other cultures by learning about different personal experiences and lifestyles.

\section{Project overview: the stages}

The situation outlined in the previous section was the general background against which our project took place. However, the internal structure of the project itself has been changing over time in response to the progressive definition of the linguistic and human profile of the minors and an ongoing analysis of the teaching experience day by day. It is possible to identify five different stages, each of which is the result of the specific choices made about the general structure of the project and its consequent repercussions at the educational level.

\subsection{Stage 1}

Integration may be identified as the first stage of our project. As seen before, it has been an a priori choice or even a "non-choice". The interaction between the minors and the highly educated students that usually attend our courses became a priority above all others. This can be considered as both a daring and a safe approach. During a later stage of the course we were forced to reconsider this choice as the progression of the course and the analysis of the results made us consider more structured and flexible educational models. Integration, however, remains the core choice for our work.

\subsection{Stage 2}

We analysed results to find out what had succeeded and what had not, what was worth keeping and what was not. The resulting actions were not conclusive but, as mentioned before, this process allowed us to gather more data in order to 
build a definitive educational model specifically aware of the new learner profile, which was considered to be "illiterate". At this stage two new types of course were introduced: literacy teaching and verbal skills-based courses. Literacy courses were focused on the skills that the students lacked: reading and writing. The target audience for this course was minors only. In the second type of course, which focused on verbal skills, the group was made up of different learner profiles that were kept together and the course content focused only on the abilities they all had in common: speaking and listening.

\subsection{Stage 3}

It was at this stage that the literacy course for minors was included in the educational offer of the School and a specific module was inserted in the program of our master's course, Teoria, progettazione e didattica dell'italiano come lingua seconda e straniera ('Italian as a second and foreign language: theory, projectbased course design and teaching'), to analyse the profile of this new learner, the illiterate or low-literate learner (Arcuri and Mocciaro 2014).

Beyond the complexity of the linguistic profile of the minors that we were dealing with, we now had to define the overall profile of those students that we had come to meet regularly and with whom we shared experiences outside of the school. What life experience, hopes or wishes were hiding behind uncertain words, laughs and shyness? What people were hidden behind those Facebook profiles who shyly became "friends"?

At this stage, two important activities that were organised within the project allowed an increasing mutual trust and facilitated a stronger, though still uncertain, relationship between the school and the minors: a workshop about Drama and Storytelling (Amoruso et al. 2015) and a series of interviews with some of the students (De Fina et al. 2016).

\subsection{Stage 4}

It was at this stage that we were able to collaborate on a theoretical and didactic level with other research centres, drawing on national and international studies on the specificity of second language learning for poorly educated learners. We did not take any further steps in our educational choices at this stage, but we elaborated on the previous ones. For the minors, this was also a very important stage where they acquired a prominent role in telling their own stories (De Fina et al. 2016). As a follow-up of the storytelling workshop, they then moved from 
oral to visual work. This consisted of three projects which allowed them to show their stories and the image they wanted to give of themselves to the public. The three projects were: the video The Butterfly Trip by Yousif Latif Jaralla, the photography exhibition A-tratti by Antonio Gervasi, and the performance Echi della lunga distanza directed by Yousif Latif Yaralla (Amoruso et al. 2015; Amoruso and D’Agostino 2016a, 2016b).

\subsection{Stage 5}

The ongoing analysis we did of the educational project was based on a strong irrefutable fact: the particularly slow learning process of these students often signified a higher risk of fossilization or actual interruption of the learning process. That fact and other more strictly linguistic features, led us all to search for alternative answers, but more importantly to better formulate questions that addressed the issue at hand. This led to our need to broaden our research boundaries by getting in touch with other research groups that were facing the same issues: the multi-country and multi-target-language research group named LESLLA (Low Educated Second Language and Literacy Acquisition).

The results obtained by our research into cognitive processes connected with the acquisition of language by LESLLA subjects, the production of educational materials designed for literacy classes, and the trialling of new teaching models. These results have been successfully distributed around public schools, particularly in those schools with a high percentage of low-educated migrant students. In the first weeks of 2016, the Italian Language School for Foreigners and the public institution responsible for adult education (known as CPIA) launched a joint project with two lines of intervention: in-service teacher training and lessons in the CPIA courses taught by teachers from the School.

In the last two years many photos and stories told in the many native languages of unaccompanied minors have been shared with scholars, researchers and educators around the world in our various conferences and symposiums.

\section{References}

Amoruso, Marcello, Mari D’Agostino \& Yousif Jaralla (eds.). 2015. Dai barconi all'università. Percorsi di inclusione linguistica per minori stranieri non accompagnati. Palermo: Scuola di lingua italiana per Stranieri.

Amoruso, Marcello \& Mari D’Agostino. 2016a. Migrant adolescents and adults with low and very low education level: Experiences and challenges for Sicilian educators. Paper 
presented at the conference Migrants \& refugees seeking a new life, Georgetown University, Washington DC, 7 April.

Amoruso, Marcello \& Mari D’Agostino. 2016b. Analfabeti plurilingui: Prospettive della ricerca e modelli di didattica. Paper presented at the International conference on acquisition and didactics of Italian, SILFI Conference, Madrid, 5-6 April.

Arcuri, Adriana \& Egle Mocciaro. 2014. Verso una didattica linguistica riflessiva. Palermo: Scuola di lingua italiana per Stranieri.

D’Agostino, Mari. 2012. Sociolinguistica dell'Italia contemporanea. Bologna: II Mulino.

D’Agostino, Mari. 2015a. Chiamo uomo chi è padrone della sue lingue. Modelli di plurilinguismo da Lampedusa in su. Paper presented at the International Conference of SLI, Malta, 24-26 settember.

D'Agostino, Mari. 2015b. L'Italia delle Italie ieri e oggi. Paper presented at the ACIS conference Fertile spaces, dynamic places: Mapping the cultures of Italy, Sydney, 1-4 July.

D’Agostino, Mari. 2015c. L'Italia linguistica plurale di ieri e di oggi. Qualche storia e alcuni dati. Paper presented at the Symposium on language in Italy in the 21st century, The British Academy, London, 19 November.

D’Agostino, Mari \& Giuseppina Sorce (eds.). 2016a. Nuovi migranti e nuova didattica. Palermo: Scuola di lingua italiana per Stranieri.

De Fina, Anna, Marcello Amoruso \& Giuseppe Paternostro. 2016b. Learning about the other: Unaccompanied minors asylum seekers in Sicily. Paper presented at Research Working Group Language - Culture - Identity on Mediterranean Basin, Paris, 25 June. 